The Influence of Commodity Programs on Acreage Response to Market Price: With an Illustration concerning Rice Policy in the United States

August 2002

\author{
Jeffrey D. McDonald* \\ and \\ Daniel A. Sumner**
}

*California Independent System Operator

**University of California Agricultural Issues Center, Department of Agricultural and Resource Economics, University of California, Davis, and Gianinni Foundation. 


\title{
The Influence of Commodity Programs on Acreage Response to Market Price: With an Illustration concerning Rice Policy in the United States
}

\author{
Abstract: \\ Farm programs often influence quantity supplied by regulating prices, providing payments and \\ directly regulating commodity marketing or input use. These same programs also influence the \\ parameters of estimated supply functions, and in particular, affect the acreage response to market \\ price. Price-quantity observations generated under such policies do not readily reveal the \\ underlying parameters of marginal cost functions which are the structural acreage response \\ parameters invariant to the policy instruments that are in place during the period from which the \\ data are generated. In this article we develop and apply an approach that uses detailed \\ information about farm program incentives and constraints to identify underlying structural \\ acreage response parameters when the data reflect behavior under complex government \\ programs.
}

The main argument and our general approach have broad applicability. We illustrate the approach with an application to the important case of rice acreage in the United States. In 1996, and 2002 program rules changed substantially. Structural parameters are needed to assess acreage response to market price under the new policies and to project acreage response under any proposed future policy change. Our empirical analysis indicates that, for U.S. rice, structural acreage response to market price is three to four times larger than acreage response under program features that were in place from 1986 to 1995 . Thus, if they were used to represent structural acreage response, estimates that fail to appropriately incorporate the program rules would be biased down by a factor of three to four. 


\section{The Influence of Commodity Programs on Acreage Response to Market Price: The Case of Rice in the United States}

\section{Introduction}

Acreage response to commodity price is a core issue of agricultural economics. Assessing acreage response is fundamental to analysis of farm programs. The inelasticity of agricultural supply functions is one of the stylized facts that have underpinned farm subsidy programs. As long ago as 1938, Galbraith and Black, using the U.S. experience from the depression years, provided evidence that farm supply was extremely inelastic. However, in a classic 1950 article, Johnson showed that the Galbraith and Black analysis confounded movements down the supply curve, due to the decline in farm output prices, with shifts of the supply curve, due to declines in input prices or increases in input supply. Thus, the structural supply function was more elastic than had been implied by a less sophisticated examination of the data.

In the half century since Johnson wrote, U.S. crop supply has continued to be heavily influenced by a complex set of farm commodity programs that affected output directly as well as acreage response to market price. This article considers the influence of farm commodity programs on acreage response and argues for a more detailed analysis of the policies themselves to uncover structural parameters. In order to better understand acreage response under alternative programs, or under no program at all, it is vital to understand in some detail how the farm programs have affected crop supply in the data available for analysis (Rucker, Thurman and Sumner). This is particularly true when, as is the case for major crops in the United States and many other countries, recent experience comes from periods when programs were particularly dominant. Unfortunately understanding the influence of complex commodity programs on acreage response parameters is difficult and many of the estimates in the literature are not useful 
for analysis outside of the policy framework that generated the data.

This article explores in detail the complex effects of the farm programs on crop acreage supply in order to derive inferences about acreage response under less restrictive farm policies. We focus particularly on the case of rice in the United States. Although similar to the programs for wheat, feed grains and cotton, the rice program has accounted for an even larger share of industry revenue and was central to supply decisions of virtually all producers.

Voluntary participation, set-aside requirements, government purchases, and price linkages all contribute to complex acreage responses by heterogeneous farmers. It is therefore difficult to interpret the results of conventional supply models that do not adequately account for these factors, nor is it a simple exercise to account for these complexities. However, by understanding the specific influence of policy rules on individual producer behavior, we can come closer to recovering the structural parameters from behavior distorted by those policy rules. This effort is particularly relevant as farm programs change, because we seldom have the needed historical data to analyze acreage response under the currently observed farm program. Thus identifying deeper structural parameters is necessary for projections as well as analysis of policy alternatives.

\section{Previous Approaches}

Previous studies of the supply of crops conditioned by farm programs have noted the differences between producer revenue (including benefits from government programs) and market price. But, in order to simplify the analysis, these studies have not considered fully the differences in grower returns across the program options, the relationships between individual program payments and market price, and the effects of planting restrictions. Three general approaches have been used model the influence of commodity programs in an estimating 
equation for acreage response. ${ }^{1}$ The approaches that have been used to model U.S. program crop acreage have been innovative but they do not allow estimation of the parameters of the marginal cost curves that are not conditional on specific commodity program attributes.

The first general approach uses a composite price index, sometimes called an effective support price (Houck and Ryan (1972), Bailey and Womack (1985), Duffy, Richardson, and Wohlgenant (1987), and Duffy, Shalishali, and Kinnucan (1994), Chen and Ito (1992) and Song and Carter (1996)). Although the exact formulas vary between studies, the concept is similar. A supply-inducing price index is constructed using a weighted combination of government support price and market price. This method saves degrees of freedom and reduces multicolinearity inherent in including several price variables as independent variables. However, the coefficient on the price index measures response to changes in the average revenue across various program options and non-program acres and is conditional on the policy under which the behavior was observed.

A second approach is to disaggregate the time series by policy regime. This approach, used by Morzuch, Weaver, and Helmberger (1980) and Lee and Helmberger (1985), allows for different response estimates across policy regimes. This approach, allows the researcher to estimate different response parameters from different policy regimes, however there are few observations for each policy regimes and one measures average rather than marginal response. Furthermore, estimates are still policy-conditioned and are not the structural supply parameters that underlie behavior under other potential policy regime and are therefore not appropriate for many significant policy questions.

A third approach used by Just (1993), Labson (1994), and Just, Rausser, and Zilberman (1995) divides the market supply curve into the proportion of total base acres that are enrolled in 
the program and those that are not. Supply for non-participants is modeled as the market supply that would have existed in the absence of any program, while supply within the program is determined by the fraction of base acres enrolled in the program that are allowed to be planted. The participation decision itself is modeled as a function of expected net returns in and out of the program. This approach draws on information from producers planting outside the program to infer the behavior of all producers if the program were removed. However, when non-program acreage is small relative to total plantings, as in the case of rice, the response estimates will include information only from the small and self-selected unrepresentative sample of producers outside the program. In addition, this approach does not exploit information about producers' structural parameters that is contained in the choice of whether or not to participate in the program nor responses within the program. Our approach below exploits information about supply behavior within the program more fully.

Theses three approaches may account for acreage response within a set of similar program rules, but are each limited in their ability to provide inferences regarding producer behavior related to policy reform or a yet unobserved set of policy rules. As Lucas (1976) pointed out, in order to use observed behavior under one set of policy rules to make inference about behavior under a different set of policy rules, one must consider carefully the nature of underlying behavioral parameters that are invariant to the policy regime. In the case of farm commodity programs, this idea applies not only to the distribution of prices and government payments, but also to the rules regarding program payments and planting restrictions.

To get a better handle on structural acreage response from behavior that takes place under complex farm programs, one must incorporate some degree of program complexity into the analysis. Section 3 provides the minimum required background concerning the rice program 
from 1985 through 1995. Although the details below apply to a specific case, our approach can be applied to obtain acreage response parameters useful for analysis of farm policy in many other contexts.

\section{A Brief Summary of the U.S. Rice Program Rules Important for Acreage Response}

The U.S. rice program began in the 1930s with the other farm programs and has been modified periodically from that point forward. As with the other major crop programs, participation in the rice program was voluntary; but unlike other programs, all but a tiny fraction of U.S. rice acreage has been grown under program rules. Farms growing rice outside the program typically had some special and temporary circumstance that precluded participation.

From 1986 to 1995, direct payments took two forms. First, deficiency payments were based on a fixed program yield for some eligible acreage that varied from year to year. The deficiency payment rate per eligible unit of quantity also varied from year as the difference between the target price (set in legislation) and the U.S. average market price. Second, marketing loan benefits were provided on all output at a rate that varied weekly based on the difference between a type-specific legislated loan rates and an adjusted world price calculated and reported by the USDA.

The 1986 to 1990 rice program provided producers with two major program options. Under the regular program option producers received deficiency payments on all planted acres (base less any acreage reduction required by the program (ARP)), and marketing loan benefits on all production. Under the $50 / 92$ option a producer planted as little as 50 percent and up to 92 percent of base less ARP. The grower received the realized deficiency payments on acres actually planted, and at minimum, the projected deficiency payment on the remainder of acreage planted up to 92 percent of maximum payment acres. ${ }^{2}$ 
From 1991 to 1995 producers participating in the regular rice program were allowed to plant from 75 percent to (perhaps) more than 100 percent of base acres, less ARP. If between 75 percent to 85 percent of base less ARP was planted to rice (Optional Flex Area, OFA), the producer was eligible for deficiency payments and loan gain payments on all land planted to rice, but was not paid deficiency payments on land shifted to another crop or idled. The producer received no deficiency payments on acres in the normal flex area (NFA), 85 percent to 100 percent of base less ARP, whether rice was planted or not. Finally, a producer was also allowed to plant rice on the flex base acreage associated with another program crop, but no deficiency payments were made on such acreage, and planting rice outside a farm's rice base was quite rare. In fact, much of rice base in the normal flex area, which was ineligible for deficiency payments was flexed to other crops or left idle (Zulauf and Tweeten (1996)). For more detail on program participation see Schnepf and Just (1995), USDA, ERS (various years).

\section{Uncovering Structural Supply Parameters under Explicit Program Rules}

By structural parameters we mean the parameters of the marginal cost curve that apply to acreage allocation to rice chosen by maximizing net revenue in a market free of explicit government intervention. We express net revenue as $\Pi=$ PYA - C(A). Then the first order condition, $\mathrm{PY}=\mathrm{C}^{\prime}\left(\mathrm{A}^{*}\right)$ is inverted to generate the acreage response equation $\mathrm{A}^{*}=\left(\mathrm{C}^{\prime}\right)^{-1}(\mathrm{PY})$, where $\mathrm{P}$ is market price, $\mathrm{Y}$ is rice yield per acre, $\mathrm{A}$ is acreage planted to rice, $\mathrm{C}$ is total cost of production and $\mathrm{C}^{\prime}$ is marginal cost. The parameters in $\mathrm{C}^{\prime}(\mathrm{A})$ are the structural parameters for acreage response to market price. Estimates of responses that do not identify these structural parameters are of limited use outside of the policy rules over which they were estimated. Moreover, if the structural parameters can be found, a set of policy rules can be applied and the acreage response under these rules can be recovered. This is particularly useful for considering 
response to policy change or acreage response to market price under an as yet unobserved set of policy rules.

In order to focus specifically on how program rules affect acreage response to market price, we must abstract from several important issues. Supply response to price may be expressed as a function of acreage response and yield response, but in this article we choose to focus on the choice of acreage. By considering acreage response, we leave aside non-land variable input use and therefore do not include endogenous yield response. Average yield is known to be a function of weather, technological innovations, output price, the price of non-land variable inputs, and the quality of marginal land. Of these factors, weather accounts for a substantial proportion of annual aggregate variation in average yields. ${ }^{3}$ Consistent with observations from 1985 to 1995 , we also do not model the choice not to produce the program crop at all, or the choice to move base acres from other crops into rice. These choices have not been empirically important.

We do not explicitly include prices of competing crops in the acreage response function developed in the next sections. But this does not mean that competing crops are unimportant for the acreage decision. As discussed in more detail below, competing crop prices are included in the econometric estimates of acreage response under specific programs, which our simulations use as a starting point. Our theoretical development and simulation model abstracts only from effects that alternative crop prices might have on the effect of commodity programs on the elasticity of rice acreage response to the price of rice. We also note that including competing crop prices in the econometrics for rice acreage response is particularly difficult because alternative crops vary substantially by location and there is not a single or small set of convenient proxy variables to represent the range of competing crop prices. 
Our model of policy influence on rice acreage also abstracts from a formal treatment of uncertainty about prices or yields, from long term decisions related to participation in farm programs or building program base. We also do not deal thoroughly with issues concerning the formation of price expectations. ${ }^{4}$ With our focus on how policy affects acreage parameters, these simplifications are unlikely to change the main results of the analysis to a significant degree. Nonetheless, our main reason for abstracting from these issues is to keep the focus on the role of commodity program rules.

Consider a model of acreage allocation that includes the choice of one of three planting options as well as the acreage allocation within each of these options. Total acreage planted to rice is the sum of acreage planted to rice in the $50 /(92,85)$ program option, the regular program option, and outside of the program:

$$
A=B \bullet\left(\rho_{50} A_{50}^{*}+\rho_{N F} A_{N F}^{*}+\rho_{N} A_{N}^{*}\right)
$$

where $\mathrm{B}$ is rice program base acres; $\rho$ is the proportion of base acres enrolled in a specific option; $\mathrm{A}_{\mathrm{i}}{ }^{*}$ is the optimal proportion of acres enrolled in that option that are planted to rice; and the subscripts 50, NF, and N correspond to 50/(92,85), normal flex, and non-program participation. For simplicity, we neglect the "optional flex" program. Few growers enrolled in this program and it was of trivial aggregate consequence (USDA, USGAO).

The proportion of acres enrolled in each of the planting options is a function of the difference in net revenue between competing options:

$$
\begin{aligned}
& \rho_{50}=\mathrm{f}_{50}\left(\Pi_{50}-\Pi_{\mathrm{NF}}, \Pi_{50}-\Pi_{\mathrm{N}}\right) \\
& \rho_{\mathrm{NF}}=\mathrm{f}_{\mathrm{NF}}\left(\Pi_{\mathrm{NF}}-\Pi_{50}, \Pi_{\mathrm{NF}}-\Pi_{\mathrm{N}}\right) \\
& \rho_{\mathrm{N}}=\mathrm{f}_{\mathrm{N}}\left(\Pi_{\mathrm{N}}-\Pi_{50}, \Pi_{\mathrm{N}}-\Pi_{\mathrm{NF}}\right), \text { and } \\
& \rho_{50}+\rho_{N F}+\rho_{N}=1 .
\end{aligned}
$$


The number of acres planted to rice in each of the three planting options, $\mathrm{A}^{*}$, have the following relationships,

$$
A_{i}^{*}=g_{i}\left(P, G_{i}, \rho_{i}\right),
$$

where the new vector $\mathrm{G}$ refers to a vector of government payments.

The response of program crop acreage to changes in anticipated price may be decomposed by differentiating equation (1) as follows:

$$
\frac{\partial \mathrm{A}}{\partial \mathrm{P}}=B \bullet\left[\frac{\partial \rho_{50}}{\partial \mathrm{P}} \mathrm{A}_{50}^{*}+\frac{\partial \rho_{\mathrm{NF}}}{\partial \mathrm{P}} \mathrm{A}_{\mathrm{NF}}^{*}+\frac{\partial \rho_{\mathrm{N}}}{\partial \mathrm{P}} \mathrm{A}_{\mathrm{N}}^{*}+\rho_{50} \frac{\partial \mathrm{A}_{50}^{*}}{\partial \mathrm{P}}+\rho_{N F} \frac{\partial \mathrm{A}_{\mathrm{NF}}^{*}}{\partial \mathrm{P}}+\rho_{\mathrm{N}} \frac{\partial \mathrm{A}_{\mathrm{N}}^{*}}{\partial \mathrm{P}}\right]
$$

The left side of equation (4) represents acreage adjustment in response to anticipated market price. The right side decomposes the acreage response into movement of acres between planting options and changes in optimal acreage planted to rice within each planting option. Together, these two types of response represent the net movement of acres within and between planting options as anticipated price changes. We view the response within a planting option, $\partial \mathrm{A}_{\mathrm{i}}^{*} / \partial \mathrm{P}$, as the marginal acreage adjustment within a planting option, net of the movement of acres between planting options. A logical empirical step from this model would be to estimate equations for $\rho_{i}$ and $\mathrm{A}^{*}{ }_{\mathrm{i}}$ jointly, and interpret the coefficient on market price from equation (3) for $\mathrm{A}_{\mathrm{i}}{ }_{\mathrm{i}}$ as representing the approximate structural parameter for marginal acreage adjustment as described above.

There are two issues associated with the interpretation of $\partial \mathrm{A}_{\mathrm{i}}{ }_{\mathrm{i}} / \partial \mathrm{P}$ in relation to the structural supply parameters that we should consider before laying out the optimization framework. First, program payments such as the deficiency and loan gain payments were often calculated using market price indexes and necessarily fluctuated with the market price. This 
relationship must be incorporated into the model to identify the structural parameters through the layer of policy rules.

The second issue is more complex. Within each of the two program options there were minimum and maximum planting restrictions that truncate the acreage response of some producers. Figure 1 shows the marginal cost curve and acreage response curve for a producer participating in the U.S. rice program. ${ }^{5}$ Marginal revenue in dollars per hundredweight is represented on the vertical axis, but since rice yield per acre is held constant, this also represents dollars per acre. Acres-planted-to-rice is on the horizontal axis with vertical dotted lines representing program acreage restrictions within each of the two program options. The decision to plant outside the program involves issues regarding the future value of base that are not easily mapped into current output price, acres planted space and are not empirically important for U.S. rice. For these reasons, the description of Figure 1 is concerned only with the two planting options considered within the program.

Let us trace out behavior as price increases. Beginning at a price just below a', the producer is constrained by the minimum planting restriction. The producer is in the program even though marginal revenue is below marginal cost because she receives a lump sum deficiency payment and would lose base if she withdraws from the program. As price increases, acreage remains at $\underline{A}_{50}$ until price rises to the point where marginal revenue equals marginal cost at quantity $\left(\underline{A}_{50}\right)$, point a' in Figure 1. Higher prices induce more rice acreage along the marginal cost curve. For a price above a, the producer would switch from the 50/(92,85) option to the (lower bound of the) normal flex option, implying a discrete jump in area planted to rice. The acreage stays at $\underline{A}_{\mathrm{NF}}$ over a range of higher prices, but then expands along the marginal cost curve as price exceeds the level consistent with point $b$. At a price consistent with point $c$, rice 
acreage is at the maximum allowed by the program and acreage will remain at this point until price is so high that, considering long run impacts as well, it is profitable to leave the rice program in order to plant additional acreage.

Comparing the supply curve traced out in Figure 1 with the linear marginal cost curve illustrated shows that acreage response to market price is truncated in both program planting options. The figure also illustrates the discrete shift in acreage planted to rice with the shift between program options.

\section{The Influence of Program Payments and Restrictions on Acreage Response to Price}

We begin by defining, in more detail, the net revenue for rice producers in each of the two program options:

$$
\begin{aligned}
& \Pi_{50}=\mathrm{PYA}+\left(\mathrm{L}-\mathrm{P}_{\mathrm{w}}\right) \mathrm{YA}+(\mathrm{T}-\overline{\mathrm{P}}) \bar{Y} \mathrm{M}-\mathrm{C}(\mathrm{A}) \\
& \text { for } \underline{\mathrm{A}}_{50} \leq \mathrm{A} \leq \overline{\mathrm{A}}_{50} \text {, and } \\
& \Pi_{\mathrm{NF}}=\mathrm{PYA}+\left(\mathrm{L}-\mathrm{P}_{\mathrm{w}}\right) \mathrm{YA}+0.85(\mathrm{~T}-\overline{\mathrm{P}}) \overline{\mathrm{Y}}(\mathrm{B}-\mathrm{ARP})-\mathrm{C}(\mathrm{A}) \\
& \text { for } \underline{\mathrm{A}}_{\mathrm{NF}} \leq \mathrm{A} \leq \overline{\mathrm{A}}_{\mathrm{NF}}, \text { where } 0<\mathrm{P}_{\mathrm{w}}<\mathrm{L}<\overline{\mathrm{P}}
\end{aligned}
$$

where the new notation and further explanation is as follows:

$\underline{\mathrm{A}}_{50}$ is 0.5 (B-ARP-NFA), lower bound for $50 / 85$

A $_{\mathrm{NF}}$ is $0.85 \mathrm{~B}-\mathrm{ARP}$, lower bound for $\mathrm{NF}$

$\overline{\mathrm{A}}_{50}$ is $\mathrm{Z}(\mathrm{B}-\mathrm{NFA}-\mathrm{ARP})$, upper bound for $50 /(92,85), \mathrm{Z}=0.85$ or $\mathrm{Z}=0.92$

$\overline{\mathrm{A}}_{\mathrm{NF}}$ is B-ARP, upper bound for NF

$\mathrm{M}$ is the maximum acres for pay under the $50 /(92,85)$ options, expressed

[0.85(1-ARP-NFA)B] or [0.92(1-ARP-NFA)B] 
$\bar{Y}$ is the individual farm's historical yield used for deficiency payment calculations $\mathrm{P}_{\mathrm{w}}$ is the expected prevailing world market price set by USDA at the time of marketing

$\overline{\mathrm{P}}$ is the expected deficiency payment price based on a national average

$\mathrm{L}$ is the loan rate (an average of $\$ 6.50$ per hundredweight. (1989/90 - 1995/96))

$\mathrm{T}$ is the target price (set at $\$ 10.71$ per hundredweight. (1990/91 - 1995/96))

C(A) represents the full opportunity cost of rice production as a function of acres of rice.

The grower maximizes net revenue in equations (5) and (6) by choosing acres planted to rice. The first order conditions derived from these equations provide the optimal acreage in any given planting option, but do not indicate whether participation in the $50 /(92,85)$ option will be more or less profitable than participating in the normal flex option. The two program options have different sources of revenue and different acreage restrictions. Therefore, within the program, two distinct net revenue functions are specified and the optima from these two options must be compared in determining the optimal acreage allocation.

Figure 1 also illustrates the acreage choice given program rules. Solid horizontal lines represent marginal revenue. The dashed horizontal line represents deficiency payments plus market price and marketing loan gains. The vertical dotted lines represent program restrictions on acreage planted to rice. A producer in the 50/(92,85) option planting somewhere between $\underline{\mathrm{A}}_{50}$ and $\overline{\mathrm{A}}_{50}$ receives the market price and loan gain on all planted acres. In addition, the producer receives a deficiency payment on $\overline{\mathrm{A}}_{50}$ acres. Under the normal flex option, a producer planting between $\underline{A}_{N F}$ and $\overline{\mathrm{A}}_{\mathrm{NF}}$ would receive the same marginal revenue per acre, but would receive a deficiency payment based on $\underline{\mathrm{A}}_{\mathrm{NF}}>\overline{\mathrm{A}}_{50}$ acres. A producer wishing to plant less than $\underline{\mathrm{A}}_{50}$ or more than $\overline{\mathrm{A}}_{\mathrm{NF}}$ must do so out of the program and would forego all government payments. The marginal cost curve representing a single producer is labeled MC in Figure 1. 
Within each program option the optimal acreage, $\mathrm{A}^{*}$, is chosen where $\partial \Pi / \partial \mathrm{A} \leq 0$. A strict inequality corresponds to a lower bound corner solution associated with program planting restrictions. For interior optima, the first order condition will allow for the identification of the acreage response function, $\mathrm{A}(\cdot)$, and thus identification of the structural acreage response $\partial \mathrm{A} / \partial \mathrm{P}$.

The first order conditions for maximizing net revenue define the acreage allocation to rice that maximizes net revenue within each planting option:

$$
\frac{\partial \Pi_{50}}{\partial \mathrm{A}}=\left(\mathrm{P}+\left(\mathrm{L}-\mathrm{P}_{\mathrm{w}}\right)\right) \mathrm{Y}-\mathrm{C}^{\prime}(\mathrm{A}) \leq 0 \Rightarrow\left(\mathrm{P}+\left(\mathrm{L}-\mathrm{P}_{\mathrm{w}}\right)\right) \mathrm{Y}=\mathrm{IP}_{50} \leq \frac{\mathrm{C}^{\prime}(\mathrm{A})}{\mathrm{Y}} \text {, and }
$$

$$
\frac{\partial \Pi_{\mathrm{NF}}}{\partial \mathrm{A}}=\left(\mathrm{P}+\left(\mathrm{L}-\mathrm{P}_{\mathrm{w}}\right)\right) \mathrm{Y}-\mathrm{C}^{\prime}(\mathrm{A}) \leq 0 \Rightarrow\left(\mathrm{P}+\left(\mathrm{L}-\mathrm{P}_{\mathrm{w}}\right)\right) \mathrm{Y}=\mathrm{IP}_{\mathrm{NF}} \leq \frac{\mathrm{C}^{\prime}(\mathrm{A})}{\mathrm{Y}}
$$

In (7) and (8), the marginal incentive price (IP) per unit of output must be less than or equal to marginal cost per unit of output, and the marginal revenue facing growers depends on expected loan gains as well as expected market price.

In Figure 1, the intersection of MC and marginal revenue defines the interior optimum for the $50 / 85$ option $\left(\mathrm{A}_{50}^{*}\right)$, where a producer may adjust acreage freely in response to changes in expected marginal revenue. The illustrated decrease in anticipated market price results in an adjustment of acreage in the 50/85 option that is truncated by the minimum planting requirement. In the normal flex option, marginal revenue is less than marginal cost, but producers are constrained by the minimum planting restriction, thus the optimum in the normal flex option is a corner solution. For the normal flex option, the first-order conditions provide a strict inequality where the marginal revenue is less than marginal cost and the producer will not adjust acreage 
over a range of marginal revenue changes.

The first order conditions for an interior solution, where we would observe a marginal acreage adjustment unobstructed by acreage restrictions, implicitly define the acreage response to market price that are unencumbered by program rules. To see these effects we can implicitly differentiate equations (7) and (8) to get:

$$
\frac{\partial \mathrm{A}_{50}}{\partial \mathrm{P}}=\frac{-\partial^{2} \Pi_{50} / \partial \mathrm{A} \partial \mathrm{P}}{-\partial^{2} \Pi_{50} / \partial \mathrm{A}^{2}}=\frac{\left(1-\frac{\partial \mathrm{P}_{\mathrm{w}}}{\partial \mathrm{P}}\right) \mathrm{Y}}{\mathrm{C}^{\prime \prime}(\mathrm{A})} \text {, and similarly }
$$

$$
\frac{\partial \mathrm{A}_{\mathrm{NF}}}{\partial \mathrm{P}}=\frac{-\partial^{2} \Pi_{N F} / \partial \mathrm{A} \partial \mathrm{P}}{-\partial^{2} \Pi_{N F} / \partial \mathrm{A}^{2}}=\frac{\left(1-\frac{\partial \mathrm{P}_{\mathrm{w}}}{\partial \mathrm{P}}\right) \mathrm{Y}}{\mathrm{C}^{\prime \prime}(\mathrm{A})} .
$$

The cost curve is assumed to be twice differentiable and well behaved (marginal cost is positive and upward sloping) so that $\mathrm{C}^{\prime}(\mathrm{A})>0$ and $\mathrm{C}^{\prime \prime}(\mathrm{A})>0$. Equations (9) and (10) have a common positive factor $\mathrm{Y} / \mathrm{C}$ ', $(\mathrm{A})$, which is equal to the standard structural acreage response $\partial \mathrm{A}^{*} / \partial \mathrm{P}$. Therefore, the bracketed term in the numerator of equations (9) and (10) determines the direction of acreage response to price changes. This bracketed term includes $\left(-\partial \mathrm{P}_{\mathrm{w}} / \partial \mathrm{P}\right)$, which shows how much the marketing loan program dampens the effect of market price on marginal revenue, and hence on output. Comparing equations (9) and (10) with the standard structural acreage response shows one of the reasons that marginal response to market incentives may be relatively weak within a commodity program.

\section{Dampened Incentives for Acreage Response for Rice in the United States}

The expected relationships $\partial \mathrm{P}_{\mathrm{w}} / \partial \mathrm{P}$ and $\partial \overline{\mathrm{P}} / \partial \mathrm{P}$ together dictate the sign and magnitude of the 
responses in the decision across program options, and the expected relationship $\partial \mathrm{P}_{\mathrm{w}} / \partial \mathrm{P}$ dictates the magnitude of the marginal acreage adjustments (equations (9) and (10)). Thus, the sign and magnitude of the marginal and option-choice acreage effects depend crucially on the relationship between growers' expectations about the three prices that enter the revenue function.

The "world price" variable $\mathrm{P}_{\mathrm{w}}$ represents what growers expect about the USDA-set loan repayment rate during the weeks relevant to their own marketing of rice (truncated from above by the loan rate). We expect a positive relationship between $\mathrm{P}_{\mathrm{w}}$, which is calculated by USDA and based on movements in the price of internationally traded rice in Thailand, and the expected price for U.S. producers, $\mathrm{P}$. The variable $\overline{\mathrm{P}}$ represents the expected national average market price received by U.S. producers as used in deficiency payment calculations (truncated from below by the loan rate and above by the target price). This expected average price is almost surely related positively to the prices that individual growers expect to receive for rice. In order

to provide some evidence on the approximate magnitudes, we estimated simple regressions with time series data by state. We found that linear regression coefficients between expected adjusted world price and expected market price range from 0.332 to 0.762 and the coefficients between expected deficiency payment price and expected market price range from 0.517 to 0.617 across states $^{6}$.

The parameters represented by these estimates are important to understanding acreage response. When marketing loan benefits are expected to be positive they dampen marginal acreage response to changes in expected market price and we observe a lower acreage response to own market price.

\section{The Choice Among Program Options}

Consider the difference in net revenue between an interior acreage allocation in the 
$50 /(92,85)$ option $\left(\mathrm{A}^{*}{ }_{50}\right)$ and the minimum acreage in the normal flex option $\left(\underline{\mathrm{A}}_{\mathrm{NF}}\right)$, as shown in Figure 1. The incentive price is the same in these two options and there is no overlap in allowed acreage. Subtracting equation (5) from equation (6), and substituting $\mathrm{A}_{50}^{*}$ and $\underline{\mathrm{A}}_{\mathrm{NF}}$ gives the difference in net revenue between these options:

$$
\Delta \mathrm{NR}=(\mathrm{P}+\mathrm{LGP}) \mathrm{Y}\left(\underline{\mathrm{A}}_{\mathrm{NF}}-\mathrm{A}^{*}{ }_{50}\right)+(\mathrm{Def}) \mathrm{Y}\left(\underline{\mathrm{A}}_{\mathrm{NF}}-\overline{\mathrm{A}}_{50}\right)-\left(\mathrm{C}\left(\underline{\mathrm{A}}_{\mathrm{NF}}\right)-\mathrm{C}\left(\mathrm{A}^{*}{ }_{50}\right)\right)
$$

where LGP is the loan gain payment, Def is the deficiency payment, and all other variables are as previously defined.

With fixed costs common to production in both options, the difference in net revenue between the $\mathrm{A}^{*}{ }_{50}$ position and the $\underline{A}_{\mathrm{NF}}$ may be expressed as

$$
\begin{aligned}
\Delta \mathrm{NR} & =\int_{A^{*}{ }_{50}}^{\overline{\mathrm{A}}_{50}}[(\mathrm{P}+\mathrm{LGP}) \mathrm{Y}-\mathrm{MC}(\mathrm{A})] \mathrm{dA}+\int_{A_{50}}^{A_{N T}}[(\mathrm{P}+\mathrm{LGP}) \mathrm{Y}+\operatorname{Def} \overline{\mathrm{Y}}-\mathrm{MC}(\mathrm{A})] \mathrm{dA} \\
& =\mathrm{S}_{1}+\mathrm{S}_{2}
\end{aligned}
$$

The first integral (from $\mathrm{A}^{*}{ }_{50}$ to $\overline{\mathrm{A}}_{50}$ ) represents net losses of producing on all eligible $50 / 85$ acres above the optimal acreage in this option. This term must be negative (by optimality conditions from equations (7) and (8)), and corresponds to area $S_{1}$ in Figure 1. The second integral (from $\overline{\mathrm{A}}_{50}$ to $\underline{\mathrm{A}}_{\mathrm{NF}}$ ) includes the additional lump sum deficiency payments that are received on the difference between the acres receiving government payments in the 50/(92,85) option ( $\left.\overline{\mathrm{A}}_{50}\right)$ and the minimum normal flex planting $\left(\underline{\mathrm{A}}_{\mathrm{NF}}\right)$. The area $\mathrm{S}_{2}$ in Figure 1 represents these additional payments, net of the additional cost of producing on this acreage. This term must be positive. A producer will choose the normal flex option over the $50 /(92,85)$ option when $\mathrm{S}_{1}+\mathrm{S}_{2}>0$, or equivalently when the additional costs for the required acreage are less than the additional deficiency payments received. This representation characterizes the participation decision for a 
grower given a set of price and payment expectations.

Consider now the sensitivity of the participation choice to changes in expected market price. The derivative of equation (12) with respect to expected price is

$$
\begin{aligned}
\frac{\partial \Delta \mathrm{NR}}{\partial \mathrm{P}} & =-\left[(\mathrm{P}+\mathrm{LGP}) \mathrm{Y}-\mathrm{C}^{\prime}(\mathrm{A} * 50)\right] \frac{\partial \mathrm{A}^{*}{ }_{50}}{\partial \mathrm{P}}+\left(1-\frac{\partial \mathrm{P}_{\mathrm{w}}}{\partial \mathrm{P}}\right) \mathrm{Y}\left(\underline{\mathrm{A}}_{\mathrm{NF}}-\mathrm{A}_{50}^{*}\right) \\
& -\frac{\partial \overline{\mathrm{P}}}{\partial \mathrm{P}}\left(\underline{\mathrm{A}}_{\mathrm{NF}}-\overline{\mathrm{A}}_{50}\right) .
\end{aligned}
$$

By the first order condition from equation (7), at the optimal acreage in $50 /(92,85)$, the first (bracketed) term on the right-hand side is equal to zero. This leaves

$$
\frac{\partial \Delta \mathrm{NR}}{\partial \mathrm{P}}=\left(1-\frac{\partial \mathrm{P}_{\mathrm{w}}}{\partial \mathrm{P}}\right) \mathrm{Y}\left(\underline{\mathrm{A}}_{\mathrm{NF}}-\mathrm{A}_{50}^{*}\right)-\frac{\partial \overline{\mathrm{P}}}{\partial \mathrm{P}} \overline{\mathrm{Y}}\left(\underline{\mathrm{A}}_{\mathrm{NF}}-\overline{\mathrm{A}}_{50}\right)
$$

The sign and magnitude of this term depends on the price relationships. Yields grew since payment yields were set, so $\mathrm{Y}>\overline{\mathrm{Y}}$, further $\left(\underline{\mathrm{A}}_{\mathrm{NF}}-\mathrm{A}_{50}{ }_{50}\right)>\left(\underline{\mathrm{A}}_{\mathrm{NF}}-\overline{\mathrm{A}}_{50}\right)$. We also expect both $\partial \mathbf{P}_{\mathrm{w}} / \partial \mathrm{P}$ and $\partial \overline{\mathrm{P}} / \partial \mathrm{P}$ to be between zero and one, and that $\partial \mathrm{P}_{\mathrm{w}} / \partial \mathrm{P}<\partial \overline{\mathrm{P}} / \partial \mathrm{P}$ for most producers. It is likely then, that $\left(1-\partial \mathrm{P}_{\mathrm{w}} / \partial \mathrm{P}\right)>\partial \overline{\mathrm{P}} / \partial \mathrm{P}$. Therefore, as the expected market price increases, the difference in net revenue between the two program options almost surely changes in favor of the normal flex option. So, whereas a negative acreage response was possible under these programs, a positive acreage response was the more likely case.

In Figure 1, when the market price is lower so is the adjusted world price, so that the marketing loan gain is larger. Similarly, the lower market price is accompanied by a lower season average price, and a higher deficiency payment. The effect of the decrease in expected market price on area $S_{1}$ in Figure 1 is the addition of area $S_{1}{ }^{\prime}$ to $S_{1}$. For the lower incentive price, 
the optimum acreage in the $50 /(92,85)$ option falls from $\mathrm{A}^{*}{ }_{50}$ to the lower bound. The area $\mathrm{S}_{1}{ }^{\prime}$ reflects a portion of the increase in relative costs associated with planting in the normal flex program instead of the 50/(92,85) program. Area $\mathrm{S}_{2}$ in Figure 1 is smaller by area $\mathrm{S}_{2}{ }^{\prime}$. Area $\mathrm{S}_{2}{ }^{\prime}$ reflects the increase in additional deficiency payments associated with planting in the normal flex option as compared to planting in the 50/(92,85) option. Notice that $\partial\left(\Pi_{\mathrm{NF}}-\Pi_{50}\right) / \partial \mathrm{P}>0$. Since $A_{N F}>A_{50}$, this reflects a positive acreage response with respect to the choice of planting option.

The acreage response attributable to the choice of planting option then depends on the comparison between net additional cost of planting area $\underline{\mathrm{A}}_{\mathrm{NF}}-\mathrm{A}^{*}{ }_{50}$ to rice and the gain in deficiency payments. The aggregate effect of this adjustment depends on the average acreage and number of producers making the shift. This adjustment relates market price to changes in aggregate acreage planted in the acreage response representation of equation (3) via the term $\rho_{\mathrm{i}}$. In the last four sections we identified the relevant acreage response associated with structural coefficients of the marginal cost function and related it to acreage response under a complex farm commodity program. We analyzed marginal adjustment within program options and discrete adjustment as growers shift from one program option to another. We highlighted the dampening effect that program payments and acreage restrictions have on acreage response. We also noted the potentially large effect that the choice of program option has on acreage response within the program. We conclude that econometric estimates of acreage response using aggregated data from the policy period do not represent the underlying marginal cost curve and cannot be interpreted in terms of the acreage response we expect under, for example, the Farm Security and Rural Investment Act of 2002. In order to measure the relevant response, it is necessary to isolate the structural marginal acreage adjustment. 


\section{The Relationship between Structural Acreage Response and Measured Response under Restrictive Commodity Programs}

In this section we present the results of a simulation model that develops the empirical relationships between acreage elasticities from the literature, which used aggregate rice acreage data generated under restrictive farm programs, and the underlying structural acreage response parameters. The simulation uses the framework developed in the previous sections. We start with a simple structural marginal cost curve for each producer that provides an acreage equation with constant elasticity with respect to price. That is

$$
\mathrm{MC}_{\mathrm{i}}(\mathrm{A})=\mathrm{a}_{\mathrm{i}} \mathrm{A}_{\mathrm{i}}{ }^{1 / \varepsilon} .
$$

For simplicity, we consider the case for which all producers have the same market acreage elasticity $\varepsilon$, but producers differ in efficiency by the scale parameter $a_{i}$ that follows a lognormal distribution. The results of this section would hold under weaker assumptions than those imposed in this simulation, but for clarity of exposition we chose to use a simplified model here. The approach we are proposing is quite general, but as usual, implementation requires that one have considerable data or make additional assumptions. Our approach makes explicit these information demands.

The parameters of the distribution function for $\mathrm{a}_{\mathrm{i}}$ were calibrated so that the model reproduces the approximate participation rates across program options that were observed for the United States over the period 1991 - 1995. Other parameter values also reflect market and policy conditions for the United States for the period 1991 - 1995. Table 1 presents more detail on the simulation including the range of price adjustments considered.

Several acreage response estimates have been reported for the U.S. rice industry under the farm program of the 1980s and early 1990s. Fan, Cramer, and Wailes (1995) report 
estimated acreage elasticities from 0.09 to 0.51 , Chen and Ito (1992) report an acreage elasticity of 0.29 , Salassi (1995) reports a range of 0.18 to 0.34 for short run acreage elasticity. These estimates account for prices of competing crops and therefore the estimates of structural elasticities that our simulation model generates similarly accounts for these relevant price movements. The acreage elasticities generally range from about 0.1 to 0.5 and are centered in the neighborhood of 0.3 , which we use as the basis for our analysis. Our base-case simulation model is calibrated, adjusting the structural market acreage elasticity $\varepsilon$, to give a total programacreage-elasticity of 0.3 , under the conditions of policies during the 1991-1995 period.

Before proceeding to the results, it is useful to list and discuss the steps used in developing our estimates (See also Table 1). (a) Write out the profit function for a typical grower that incorporates the policy rules and relationships. The profit function used in the simulation here is represented by equations (5) and (6). (b) Select the initial policy and market parameter values that conform to the regulations and market settings for the commodity and policy of interest. (c) Choose a density function and initial density-function parameters for at least one of the marginal cost equation parameters. The variation across farms is required to reflect the fact that not all farms participate in the same program option or plant the same acreage, even if they share price expectations. We use the lognormal density and set $\varepsilon$ while allowing variation in the scale parameter of the marginal cost function. Next draw a random sample of grower cost parameters from this density function. (d) Calculate the profit maximizing planted acres within the program for each simulated-grower. Tabulate the profit maximizing acreage for each grower given an initial set of market and program parameter values. (e) Set the marginal cost density parameters so that the aggregate acreage resulting from the simulation match those observed during the initial policy regime modeled. (f) Calibrate the underlying 
structural supply elasticity, or no-program response to price, so that the simulated program elasticity matches the within-program econometric estimates. As Table 1 details, we shock the system with representative price increases and decreases and use responses to calculate arc elasticities. By adjusting the no-program elasticity implied by the marginal cost curve, the model can be calibrated to yield a program acreage elasticity that matches those estimated via econometric techniques or found in the literature. This step yields the structural no-program elasticity that corresponds to the program elasticity from the econometric literature. (g) Evaluate the sensitivity of the model. We simulated aggregate grower response by inducing alternative price or program changes. The sensitivity of the model to the initial parameter values was evaluated by adjusting the starting values for market price, payment prices, program enrollment, and estimated price relationships. The specified model used in this study was remarkably robust to starting values for market and program parameters including the use of a truncated normal density instead of a lognormal.

Important parameters for this application include the two calibrating parameters; participation in the 50/85 program and the proportion of 50/85 participants planting the minimum required acreage. To check for sensitivity of the results, the participation rate and the proportions were each adjusted by \pm 10 percent and the simulation was re-run with very small effects on the implied no-program acreage response elasticities. Initial values for the average market price, average deficiency payment price, and average loan gain payment price were adjusted by \pm 20 percent again with only minor effects on results.

Table 2 presents results that show the underlying structural supply acreage elasticity consistent with the within- program elasticity of 0.3 . The most important numbers in Table 2 are the ratios of the structural elasticity of the acreage supply function and the program-based 
elasticity of program acreage. This ratio ranges from 2.8 to 3.8 . This result means that the typically-estimated acreage response elasticity based on data conditioned on farm program incentives and restrictions will be about three to four times smaller than the underling structural acreage response elasticity. And, for rice this is a conservative estimate because the 1991 - 1995 program rules allowed more flexibility than previous programs.

Each column in Table 2 presents results for different values for the price relationships $\partial \overline{\mathrm{P}} / \partial \mathrm{P}$ and $\partial \mathrm{P}_{\mathrm{w}} / \partial \mathrm{P}$. Case 1 is based on the approximate values reported above: $\partial \overline{\mathrm{P}} / \partial \mathrm{P}=0.75$ and $\partial \mathrm{P}_{\mathrm{w}} / \partial \mathrm{P}=0.50$. The second column shows the effect of a closer relationship between the adjusted world price and the market price expected by U.S. growers. We also considered other relationships. Generally, the higher the relationship the greater the dampening of the structural acreage response.

The first row in Table 2 is the program acreage elasticity with respect to the incentive price, which is the starting point for the simulations. The value shown, 0.3 , corresponds to an elasticity estimate from an acreage equation with the expected incentive price and other relevant independent variables on the right hand side. Given program parameters noted in Table 1 and the price relationships shown in the column heading, we found that a program acreage elasticity of 0.3 corresponds to the structural acreage elasticity of 0.91 (reported in row 8 of Table 2). The second column of Table 2 shows the effects of different values for the price relationships. With a higher $\partial \mathrm{P}_{\mathrm{w}} / \partial \mathrm{P}$ less of the market price change is reflected in the incentive price change; there is more dampening from the marketing loan program. When $\partial \overline{\mathrm{P}} / \partial \mathrm{P}$ is higher, the deficiency payment is expected to be smaller. The implied market elasticity of 1.14 corresponding to $\partial \overline{\mathrm{P}} / \partial \mathrm{P}=0.75$ and $\partial \mathrm{P}_{\mathrm{w}} / \partial \mathrm{P}=0.75$ is significantly higher than market elasticity in the base case. The figures in rows 2 through 7 between the program and structural acreage elasticities 
decompose the relationship of the overall acreage elasticities into adjustments within and across program options. Rows 2 and 3 show the 50/85 acreage elasticity and the normal flex acreage elasticities. These measures reflect those that would be estimated from a model with expected incentive price regressed on acres planted to rice within either program option. The elasticity for the $50 / 85$ program, -0.11 , is lower than the total program elasticity in the base case. This response represents both acreage that leaves the 50/85 option and acreage that adjusts within the $50 / 85$ option. The elasticity for the normal flex option, 0.39 , is higher because it reflects both acreage added to the NFA option with a price increase and acreage adjustments within the NFA option. The weights are calculated using the average acres planted in each option prior to a price change. The weighted sum of these two elasticities is equal to the total program acreage elasticity.

The next three rows in Table 2 show acreage elasticities net of producers who switch program options. For the total program elasticity, this is equal to 0.25 in the base case. This elasticity is decomposed into the acreage elasticity for the producers who begin and stay in the $50 /(92,85)$ program option, 0.63 ; and those who begin and stay in the normal flex option, 0.17 . The total elasticity is produced by adding the acreage elasticity of producers who switch program options, 7.46 , weighted by the small initial proportion of acres that switch, shown in row $7 .^{7}$

The acreage response for producers who switched program options is quite high. This result is the direct consequence of the difference between acreage allowed under the 50/85 program and the minimum allowed average under the NFA option. The overall effect of the option switching on total elasticity is limited by the small share of producers that are on the margin of switching program options in response to $10 \%$ and $20 \%$ changes in expected market prices. 
In order to better understand how particular program features affect the estimates, we calculated both the acreage elasticity without the incentive dampening effects of program payments and without acreage restrictions and program options. These two elasticities are reported in rows 9 and 10 in Table 2 . In the base case, the elasticity of program acres without the incentive dampening effects of program payments is 0.75 (row 9). This elasticity was calculated by setting the two price relationships to zero and re-running the simulation. The price relationships were set to zero for this calculation for all three cases, therefore this elasticity is the same for the base case as well as Case 2 and Case 3 .

Alternatively, we apply only the incentive dampening effect of the price relationships to the structural elasticity ( 0.90 for the base case, in row 8$)$, which is the structural acreage elasticity without the program payments or planting restrictions. Equations (9) and (10) show that the acreage response under price dampening will be smaller by a factor of $\left(1-\partial \mathrm{P}_{\mathrm{w}} / \partial \mathrm{P}\right)$, which is $(1-0.50)=0.50$ for the base case. Thus, the incentive dampening effect alone reduces the elasticity by half to 0.45 (row 10).

The simulations that account for the incentive dampening effect alone are of particular interest because the FAIR Act and FSRI Act removed the planting restrictions but left the marketing loan program in place. The simulations suggest that, with $\partial \mathrm{P}_{\mathrm{w}} / \partial \mathrm{P}=0.5$, the FAIR Act and FSRI Act acreage response elasticity of 0.45 is consistent with a structural elasticity of 0.90 and a program elasticity of 0.30 estimated from data generated under earlier program regulations. These effects (incentive dampening and acreage restrictions/program options) are not additive in general. Coincidentally, the two grouped effects appear to be additive in the base case.

The results presented in Table 2 show that acreage response under complex commodity programs comprise a variety of partial responses reflecting dampening, truncation and option 
switching. Such responses each have a structural acreage response parameter imbedded within them, and these parameters may be extracted from observed behavior and other data. We have found that under reasonable assumptions, the program acreage response was far smaller than the underlying structural acreage response parameter.

\section{Concluding Comments}

This paper shows how to interpret price-acreage relationships under government programs. We also show how common econometric estimates of acreage response must be modified before they can apply to analysis of deregulation or to analysis of acreage response under alternative government programs. Given the corners and constraints within program options, option switching, and incentive dampening, most common econometric estimates of acreage response are difficult to interpret with regard to structural acreage response parameters. Our illustration, using data for U.S. rice, found that the structural acreage response parameter was three to four times the magnitude of that estimated under program rules.

We show that by carefully incorporating program rules into the model we can better understand the relationship between structural supply parameters and the acreage behavior expected under a specific set of farm program rules. We argue that this general approach, when extended and refined is applicable to other situations, especially when combined with a simulation approach, which we also illustrate.

The complexity of program rules, the interaction of the rules with acreage decisions, and the limited availability of data from reasonably consistent policy regimes all suggest that researchers should consider approaches to supply estimation that are broader than conventional econometric or programming methods. Problems in macroeconomics similar to ours have been approached recently by using calibration and simulation techniques (Hansen and Heckman 
(1996)). A body of literature that uses simulation-based estimation techniques to combine the detail available in mathematical programming models with desirable statistical properties are also developing rapidly (Stern (1997)). This approach seems to have promise for estimating structural acreage response parameters in the context of complex commodity programs. 


\section{References}

Bailey, K. and A. Womack. "Wheat Acreage Response: A Regional Econometric Investigation." Southern Journal of Agricultural Economics. 17(1985): 171-180.

Burt, Oscar R., and Virginia E. Worthington. "Wheat Acreage Supply Response in the United States." Western Journal of Agricultural Economics. 13(1988): 100-111.

Chavas, J-P., R. D. Pope, and R. S. Kao. "An Analysis of the Role of Futures Prices, Cash Prices, and Government Programs in Acreage Response." Western Journal of Agricultural Economics. 8(1983):27-33.

Chen, D. and S. Ito. "Modeling Supply Response with Implicit Revenue Functions: A PolicySwitching Procedure for Rice.” American Journal of Agricultural Economics. 74(1992): 186-196.

Choi, J. and P. Helmberger. "Acreage Response, Expected Price Functions, and Endogenous Price Expectations." Journal of Agricultural and Resource Economics. 18(1993):37-46.

Choi, J. and P.G. Helmberger. "How Sensitive are Crop Yields to Price Changes and Farm Programs?” Journal of Agric. and Applied Econ. 25 (July 1993): 237-244.

Coats, R.E. and Gail L. Cramer "Rice Policy." Cooperative Extension Background Paper for the 1995 Farm Bill, University of Arkansas. 1994.

Colman, David. "A Review of the Arts of Supply Response Analysis." Review of Marketing and Agricultural Economics. 51(1993): 201-230.

Cramer, G.L., E.J. Wailes, B. Gardner, and W. Lin "Regulation in the U.S. Rice Industry, 19651989.” American Journal of Agricultural Economics. 72(1990): 1056-1065.

Duffy, P., A., K. Shalishali, and H. Kinnucan. "Acreage Response Under Farm Programs for Major Southeastern Field Crops." Journal of Agricultural and Applied Economics. 26(1994): 367-378.

Duffy, Patricia A., C. Robert Taylor, Danny L. Cain, and George J. Young. "The Economic Value of Farm Program Base." Land Economics. 70(1994): 318-329.

Duffy, Patricia A. and C. Robert Taylor. "Effects on a Corn-Soybean Farm of Uncertainty about the Future of Farm Programs." American Journal of Agricultural Economics. 76(1994): 141-152.

Duffy, Patricia A., James W. Richardson, and Michael K. Wohlgenant. "Regional Cotton Acreage Response." Southern Journal of Agricultural Economics. 19(1987): 99-109.

Eckstein, Z. "A Rational Expectations Model of Agricultural Supply." Journal of Political 
Economy. 92(1984): 1-19.

Fan, Shenggen, G. Cramer, and E. Wailes. "U.S. Rice Policy Reforms: Impact on Production, Farmers' Income, and Government Budget." Paper presented at the annual AAEA meetings, August 1995.

Fisher, B.S. and C. Tanner. "The Formulation of Price Expectations: An Empirical Test of Theoretical Models." American Journal of Agricultural Economics. 60(1978): 245-248.

Galbraith, J.K. and J.D. Black. "The Maintenance of Agricultural Production during Depression: The Explanations Reviewed." Journal of Political Economy. 46(1938): 305-323.

Gardner, B. "Futures Prices in Supply Analysis." American Journal of Agricultural Economics. 58(1976): 81-84.

Grant, W.R., J. Beach, and W. Lin. "Factors Affecting Supply, Demand, and Prices of U.S. Rice." Staff Report No. AGE840803. Economic Research Service, U.S. Department of Agriculture, Washington, DC. 1984.

Hansen, Lars Peter and James J. Heckman. "The Empirical Foundations of Calibration." Journal of Economic Perspectives. 10(1996): 87-104.

Houck, J.P. and M.E. Ryan. "Supply Analysis for Corn in the United States: The Impact of Changing Government Programs." American Journal of Agricultural Economics. 54 (1972): 184-191.

Johnson, D.G. "The Nature of the Supply Function for Agricultural Products," American Economic Review. 40 (1950): 539-563.

Just, R.E. "Discovering Production and Supply Relationships: Present Status and Future Opportunities." Review of Marketing and Agricultural Economics. 61(1993): 11-40.

Just, R. E. "Some Guiding Principles for Empirical Production Research in Agriculture." Working Paper. April 2000. University of Maryland.

Just, R. E., D. Zilberman, and G. Rausser. "Modeling Policy Reform in the U.S. Wheat and Feed Grain Sectors." GATT Negotiations and the Political Economy of Policy Reform. Ed. Rausser, G. C. Heidelberg: Springer-Verlag, 1995. 175-252.

Labson, B.S. "Modeling Distortionary Aspects of the U.S. Wheat Program and Policy Reform." Journal of Policy Modeling. 16(1994): 237-263.

Lee, D. and P. Helmberger. "Estimating Supply Response in the Presence of Farm Programs." American Journal of Agricultural Economics. 67(1985): 192-203.

Lin, William and Andrew Washington. "Measuring Supply Response Under the 1996 Farm Act: 
The Case of Corn and Soybeans." Paper presented at the AAEA Annual Meeting in Toronto, Canada, July 27-30, 1997.

Lin, W., P. C. Westcott, R. Skinner, S. Sanford, and D. G. De La Torre Ugarte. "Supply Response Under the 1996 Farm Act and Implications for the U.S. Field Crops Sector." USDA, ERS Technical Bulletin Number 1888. July 2000. Washington, D.C.

Lucas, R. "Econometric Policy Evaluation: A Critique." Journal of Monetary Economics., Supplementary Series 1976, I, pp.19-46.

McIntosh, C. S., and K. H. Shideed. "The Effect of Government Programs on Acreage Response Over Time: The Case of Corn Production in Iowa." Western Journal of Agricultural Economics. 14(1989):38-44.

Morzuch, B.J., R.D. Weaver, and P.G. Helmberger. "Wheat Acreage Supply Response Under Changing Farm Programs." American Journal of Agricultural Economics. 62(1980): 29-37.

Nerlove, Marc. "Estimates of the Elasticities of Supply of Selected Agricultural Commodities." Journal of Farm Economics. 38(1956):496-509.

Rucker, Randal R., Walter N. Thurman and Daniel A. Sumner. "Restricting the Market for Quota: An Analysis of Tobacco Production Rights With Corroboration from Congressional Testimony." Journal of Political Economy. 103(February 1995):142-175.

Salassi, Michael E. "The Responsiveness of U.S. Rice Acreage to Price and Production Costs." Journal of Agricultural and Applied Economics. 27(1995): 386-399.

Schnepf, Randall D. and Bryan Just. "Rice - Background for 1995 Farm Legislation.” United States Department of Agriculture, Economic Research Service. Agricultural Economic Report Number 713. April 1995.

Shideed, K. H. and F. C. White. "Alternative Forms of Price Expectations in Supply Analysis for U.S. Corn and Soybean Acreages.” Western Journal of Agricultural Economics. 14(1989a):281-292.

Song, JooHo and Colin A. Carter. "Rice Trade Liberalization and Implications for U.S. Policy." American Journal of Agricultural Economics. 78(1996):

Stern, Steven. "Simulation-Based Estimation.” Journal of Economic Literature. 35(1997): 20062039.

United States Department of Agriculture, Economic Research Service. "Rice - Situation Outlook Report." various years.

U.S. General Accounting Office "Rice Program: Government Support Needs to be Reassessed." 
GAO/RCED-94-88, May 1994.

Wang, Jirong, Eric J. Wailes, and Gail L. Cramer. "Factors Affecting A Rice Farmer's Decision on Choice and Level of Program Participation." Paper presented at the American Agricultural Economics Association Annual Meeting, Summer 1996.

Westcott, P.C. "Planting Flexability and Land Allocation." American Journal of Agricultural Economics. 73(1991):1105-1115.

White, Fred C. "Aggregate Effects of Base Building." Working Paper, Department of Agricultural and Applied Economics, University of Georgia. 1996

Zulauf, Carl and Luther Tweeten. "The Post-Commodity-Program World: Production Adjustments of Major U.S. Field Crops.” Choices Winter, 1996. pp.8-10. 


\section{Table 1: Description of Simulation Model and Calibration Including Parameter Values}

Producer marginal cost curve:

$\mathrm{MC}_{\mathrm{i}}(\mathrm{A})=\mathrm{a}_{\mathrm{i}} \mathrm{A}_{\mathrm{i}}{ }^{1 / \varepsilon}$ where $\mathrm{a}_{\mathrm{i}}$ is distributed $\log -\mathrm{N}(\mu, \sigma)$ and $\mu$ and $\sigma$ are calibrated to produce a 70 percent participation rate in the normal flex option for the base case, consistent with that found in the United States over the period 1991 - 1995, and 1/3 of the base acreage enrolled in the 50/85 option is at the lower bound.

\section{Model parameters}

Parameters used are consistent with values for the United States over the period 1991 - 1995.

Minimums, maximums and standard deviations for the price variables are shown in parentheses.

Total base, ARP

Average yield, Program yield

Target price, Loan rate

Average adjusted world price

Average deficiency payment price

Average market price

$\partial \mathrm{P}_{\mathrm{w}} / \partial \mathrm{P}, \partial \overline{\mathrm{P}} / \partial \mathrm{P}$

Average normal flex participation rate

Proportion of 50/85 base at lower bound 4,000,000 acres, 3 percent

$60 \mathrm{cwt} / \mathrm{acre}, 48 \mathrm{cwt} / \mathrm{acre}$

$\$ 10.71 / \mathrm{cwt}, \$ 6.50 / \mathrm{cwt}$

$\$ 5.62 /$ cwt $(\$ 4.18, \$ 6.21,0.46)$

$\$ 7.06 /$ cwt $(\$ 6.50, \$ 7.64,0.49)$

$\$ 7.40 /$ cwt $(\$ 5.89, \$ 9.15,1.25)$

0.75 (base case), 0.50 (base case)

0.70 (used in calibration)

0.33 (used in calibration)

\section{Simulation procedure}

- Distribution parameters for cost intercepts calibrated on observed average participation rates.

- Three initial incentive prices ( \pm 10 percent centered on the average incentive price). Each incentive price adjusted by \pm 10 percent, and resulting prices calculated based on price relationships $\partial \mathrm{P}_{\mathrm{w}} / \partial \mathrm{P}$ and $\partial \overline{\mathrm{P}} / \partial \mathrm{P}, \mathrm{IP}=\mathrm{P}+\mathrm{LGP}$, and Def $=(\mathrm{TP}-\overline{\mathrm{P}})$.

- Optimal producer program acreage calculated using the initial and adjusted prices. Elasticities for each of these adjustments calculated, weighted, and summed.

- The weighting scheme, interpreted as the likelihood of observing a \pm 10 percent change from the initial price, follows (row $=$ origin and column $=\%$ change)

$\underline{10 \%} \quad \underline{-10 \%} \quad \underline{10 \%} \underline{-10 \%} \quad \underline{10 \%} \underline{-10 \%}$

$10 \%$ above base $\quad 0.06 \quad 0.24 ; \quad$ Base $0.20 \quad 0.20 ; \quad 10 \%$ below base $0.24 \quad 0.06$ 
Table 2: Elasticities of Structural and Program Acreage Response for U.S. Rice

\begin{tabular}{|c|c|c|c|}
\hline Elasticity $^{\mathrm{a}}$ & $\begin{array}{l}\text { Case } 1 \\
(0.75,0.5)^{\mathrm{b}}\end{array}$ & $\begin{array}{l}\text { Case } 2 \\
(0.5,0.5) \\
\end{array}$ & $\begin{array}{l}\text { Case } 3 \\
(0.75,0.75) \\
\end{array}$ \\
\hline $\begin{array}{l}\text { Elasticity of } \\
\text { Program Acreage }\end{array}$ & 0.30 & 0.30 & 0.30 \\
\hline $\begin{array}{l}\text { Elasticity of } 50 / 85 \text { Acres } \\
\text { (weights) }\end{array}$ & $\begin{array}{l}-0.107 \\
(0.185)\end{array}$ & $\begin{array}{l}-0.457 \\
(0.185)\end{array}$ & $\begin{array}{l}1.132 \\
(0.185)\end{array}$ \\
\hline $\begin{array}{l}\text { Elasticity of NF Acres } \\
\text { (weight) }\end{array}$ & $\begin{array}{l}0.393 \\
(0.815)\end{array}$ & $\begin{array}{l}0.471 \\
(0.815)\end{array}$ & $\begin{array}{l}0.111 \\
(0.815)\end{array}$ \\
\hline $\begin{array}{l}\text { Elasticity of Total Program } \\
\text { Acreage (w/o option switching) } \\
\text { (weight) }\end{array}$ & $\begin{array}{l}0.248 \\
(0.992)\end{array}$ & $\begin{array}{l}0.229 \\
(0.990)\end{array}$ & $\begin{array}{l}0.324 \\
(0.995)\end{array}$ \\
\hline $\begin{array}{l}\text { Elasticity of } 50 / 85 \text { Acres } \\
\text { (w/o option switching) } \\
\text { (weight) }\end{array}$ & $\begin{array}{l}0.628 \\
(0.182)\end{array}$ & $\begin{array}{l}0.590 \\
(0.181)\end{array}$ & $\begin{array}{l}0.789 \\
(0.183)\end{array}$ \\
\hline $\begin{array}{l}\text { Elasticity of NFA Acres } \\
\text { (w/o option switching) } \\
\text { (weight) }\end{array}$ & $\begin{array}{l}0.165 \\
(0.810)\end{array}$ & $\begin{array}{l}0.152 \\
(0.809)\end{array}$ & $\begin{array}{l}0.221 \\
(0.813)\end{array}$ \\
\hline $\begin{array}{l}\text { Elasticity of Program } \\
\text { Option Changes } \\
\text { (weight) }\end{array}$ & $\begin{array}{l}7.460 \\
(0.008)\end{array}$ & $\begin{array}{l}7.189 \\
(0.010)\end{array}$ & $\begin{array}{l}-12.074 \\
(0.005)\end{array}$ \\
\hline $\begin{array}{l}\text { Structural Elasticity of the } \\
\text { Acreage Supply Function }\end{array}$ & 0.901 & 0.847 & 1.135 \\
\hline $\begin{array}{l}\text { Ratio of program to structural } \\
\text { Acreage elasticity }\end{array}$ & 3.0 & 2.8 & 3.8 \\
\hline $\begin{array}{l}\text { Elasticity with only: } \\
\text { Acreage restrictions } \\
\text { Price and payment filtering }\end{array}$ & $\begin{array}{l}0.750 \\
0.451\end{array}$ & $\begin{array}{l}0.750 \\
0.424\end{array}$ & $\begin{array}{l}0.750 \\
0.284\end{array}$ \\
\hline
\end{tabular}

a Acreage elasticities are calculated with respect to incentive price.

$\mathrm{b}$ Values in parenthesis represent $\partial \mathrm{P}_{\mathrm{w}} / \partial \mathrm{P}$ and $\partial \overline{\mathrm{P}} / \partial \mathrm{P}$ used in the simulation reported in that column. 


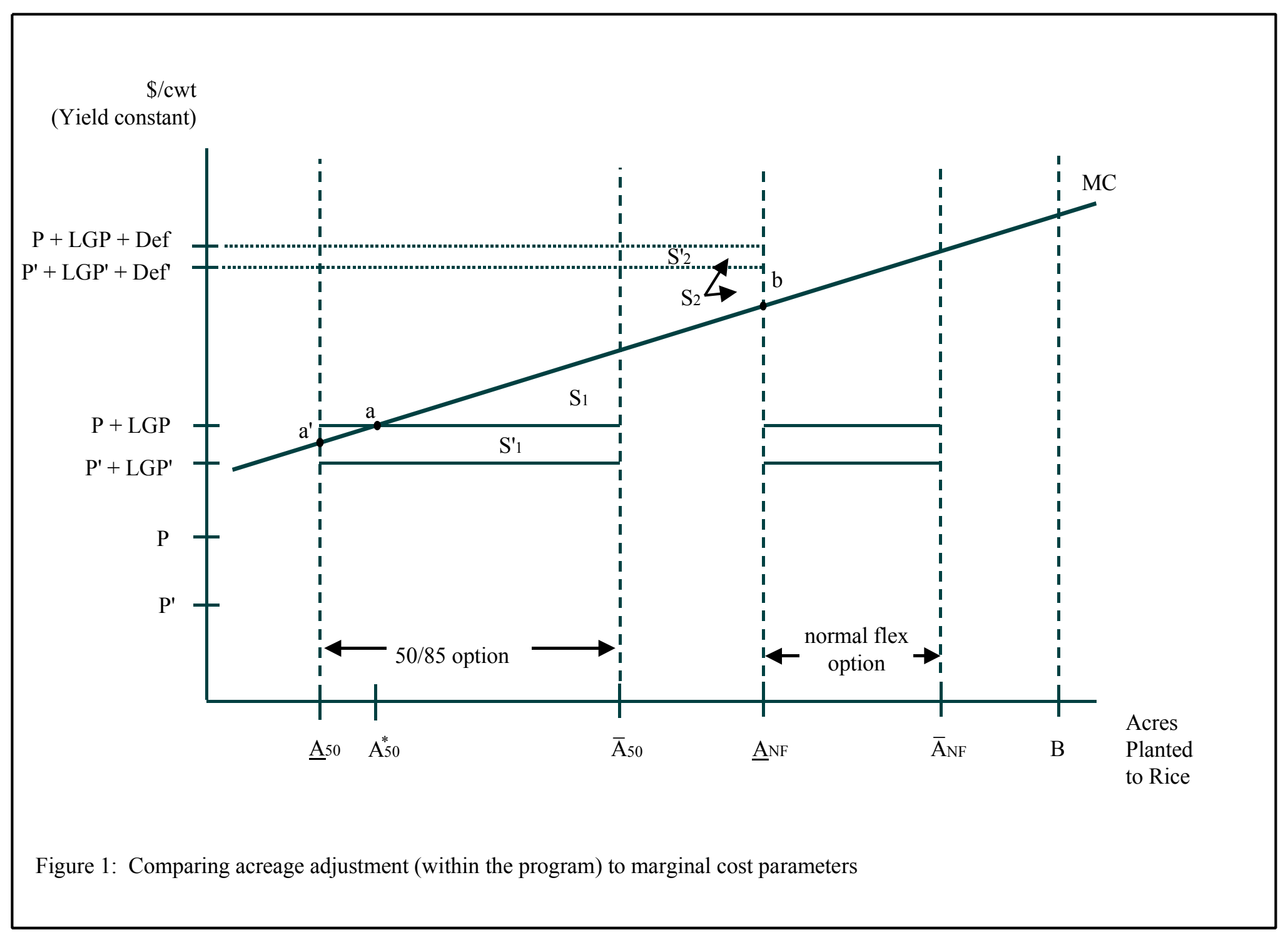





\section{Notes}

${ }^{1}$ Nerlove (1956) and Burt and Worthington (1988) should be mentioned here as well, although they focus more on the dynamic relationships rather than response under complex program rules. In addition to the three general approaches discussed here, McIntosh and Shideed (1989) use time-varying parameters to estimate response across regimes as an alternative to temporal disaggregation. Coleman (1983) and Just (2000) provide perspectives on the broader literature.

${ }^{2}$ For 1994 and 1995, the program was modified such that 85 percent replaced the 92 percent that applied in prior years. Henceforth we will refer to the program as 50/(92,85).

${ }^{3}$ Fan, Cramer, and Wailes (1995) and Song and Carter (1996) estimate the supply response for rice with separate yield responses. Choi and Helmberger (1993b) show that the choice of planted acreage embodies most of the effect of program rules on supply.

${ }^{4}$ Our empirical approach to price expectations is limited by the ten-year policy regime. Chavas, Pope, and Kao (1983); Gardner (1976); Choi and Helmberger (1993a); Eckstein (1984); Fisher and Tanner (1974); and Shideed and White (1989) focus more on price expectations.

${ }^{5}$ In the simulation model marginal costs for each producer are indexed by individual intercepts.

${ }^{6}$ An appendix available from the authors discusses estimation of these relationships in detail.

${ }^{7}$ See Lin and Washington (1997), Labson (1995), Rausser, et al. (1995), and Wang, et al. (1996). 